\title{
EVALUASI PENGGUNAAN OBAT PADA PASIEN OSTEOARTRITIS DI INSTALASI RAWAT JALAN RSUD DR. M. ASHARI PEMALANG PERIODE MARET-APRIL 2018
}

\author{
Fithri Zahara $\mathbf{S}^{1)}$, Ebta Narasukma $\mathrm{A}^{\mathbf{1}^{*}}$, Maria Caecilia N.S.H ${ }^{1)}$ \\ ${ }^{1}$ Sekolah Tinggi Ilmu Farmasi "Yayasan Pharmasi Semarang" \\ "E-mail:sukma.anggraeny@gmail.com
}

\section{INTISARI}

Osteoartritis (OA) adalah penyakit sendi degeneratif yang ditandai dengan adanya kerusakan kartilago dan sering terjadi pada pasien usia lanjut. Obat-obatan yang sering digunakan pada terapi OA adalah parasetamol, antiinflamasi non steroid (AINS), serta glukosamin dan kondroitin (suplemen makanan). Penelitian ini bertujuan untuk mengidentifikasi profil pasien OA, meliputi jenis kelamin, usia dan mengevaluasi penggunaan obat (tepat pasien, tepat indikasi, dan tepat dosis) serta potensi interaksi obat pada pasien OA. Penelitian ini merupakan penelitian non eksperimental dengan menggunakan rancangan deskriptif non analitis. Data diambil secara retrospektif dengan metode purposive sampling dari rekam medis pasien OA rawat jalan di RSUD Dr. M. Ashari Pemalang periode Maret-April 2018. Hasil penelitian ini menunjukkan bahwa pasien telah mengidap penyakit OA selama 1-2 tahun (40\%), sebagian besar perempuan $(72,94 \%)$ dengan rentang usia 46-55 tahun (39\%). Pasien umumnya memiliki tingkat pendidikan SD/sederajat (41\%) dan 43,53\% di antaranya adalah pasien dengan kategori overweight (IMT 25,00-29,99). Semua obat-obatan yang diresepkan dokter untuk terapi OA telah tepat indikasi dan tepat pasien. Sebanyak $80,95 \%$ obat-obatan yang diresepkan telah tepat dosis dan 19,05\% kasus peresepan obat masuk ke dalam kategori dosis kurang. Potensi interaksi obat terjadi pada 30,58 \% pasien, dengan jumlah kasus sebanyak 29 kasus.

Kata kunci: Osteoartritis, evaluasi penggunaan obat, pasien rawat jalan

\section{ABSTRACT}

Osteoarthritis $(O A)$ is a degenerative joint illness characterized by cartilage destruction and often found on older people. The drugs commonly used to treat OA symptoms is paracetamol, nonsteroidal anti-inflammatory drugs (NSAIDs), food supplements such as glucosamine and chondroitin. The purposes of these studies are identifying the OA patient's characteristics (including gender and age), drug use evaluation based on the right patient, indication, and dose, as well as the potency of drug interactions on OA patients. This research is non-experimental research with a non-analytical descriptive design. The data was collected retrospectively with a purposive sampling method from outpatients OA medical records in RSUD Dr. M. Ashari Pemalang (March to April 2018 period). The results of this study indicate that patients have suffered OA for 1-2 years (40\%), generally women (72.94\%) with an age range of 46-55 years (39\%). Most patients have an elementary school educational background (41\%), and $43.53 \%$ of them are overweight (BMI 25.00-29.99). All medicines prescribed for OA patient therapy have been the right indication and patient. As many as $80.95 \%$ of the prescribed medicines had the right dose, and 19.05\% of prescription drugs case categorized as underdosing. Drug interactions potency occurs in $30.58 \%$ of patients, with 29 cases.

Keywords: Osteoarthritis, drugs use evaluation, outpatient 
*Corresponding author:

Ebta Narasukma Anggraeny

Sekolah Tinggi Ilmu Farmasi "Yayasan Pharmasi Semarang"

Jalan Letjend Sarwo Edie Wibowo Km. 1 Plamongansari-Pucanggading, Semarang 50193

E-mail: sukma.anggraeny@gmail.com

\section{PENDAHULUAN}

Osteoarthritis (OA) adalah radang sendi yang paling umum terjadi pada usia lanjut (> 60 tahun), terjadi pada $18 \%$ wanita dan $10 \%$ pria di seluruh dunia (Woolf dan Plefger, 2003). Osteoartritis merupakan penyakit muskuloskletal yang berkembang dengan lambat, biasanya mempengaruhi sendi, terutama di artrodial perifer dan rangka aksial. Penyakit ini ditandai dengan kerusakan dan hilangnya kartilago artikular yang berakibat pada pembentukan osteofit, rasa sakit, pergerakan yang terbatas, deformitas, dan ketidakmampuan bergerak (Sukandar dkk., 2008). Pengobatan OA bertujuan untuk mengurangi gejala rasa sakit dan kekakuan, mempertahankan fungsi tulang rawan, meningkatkan mobilitas sendi, memelihara dan meningkatkan kualitas hidup pasien (Buys dan Elliot, 2008).

Tatalaksana terapi OA sangat ditentukan oleh tingkat keparahan dan rasa nyeri yang diderita pasien (Depkes RI., 2006). Obat yang sering digunakan untuk mengatasi nyeri dalam pengobatan OA adalah parasetamol dan antiinflamasi non steroid (AINS) serta suplemen makanan yang mengandung glukosamin dan kondroitin sebagai pelumas sendi. Pemilihan dan penggunaan terapi obat yang tepat untuk pasien OA dapat menentukan keberhasilan pengobatan. Oleh karena itu, perlu dilakukan evaluasi penggunaan obat pada pasien OA untuk meningkatkan efektivitas dan keamanan terapi pada masa yang akan datang. Evaluasi penggunaan obat dalam penelitian ini bertujuan untuk mengetahui apakah obat-obat yang digunakan untuk terapi OA pada pasien rawat jalan RSUD Dr. M. Ashari Pemalang saat ini telah tepat pasien, tepat indikasi dan tepat dosis. Evaluasi penggunaan obat juga dilakukan untuk menilai adanya potensi interaksi obat pada obatobat yang digunakan.

\section{METODE PENELITIAN}

Penelitian ini merupakan penelitian non eksperimental. Objek penelitian ini adalah data rekam medis pasien di Instalasi Rawat Jalan RSUD Dr. M. Ashari Pemalang periode Maret-April 2018 yang memenuhi kriteria inklusi (diagnosa: OA, dengan atau tanpa penyakit penyerta). Kriteria eksklusi yang digunakan adalah data rekam medis pasien tidak lengkap dan atau tidak terbaca. Data penelitian diambil secara retrospektif pada data rekam medis pasien dengan menggunakan teknik purposive sampling dan selanjutnya dianalisis secara deskriptif.

Analisis tepat dosis dilakukan dengan cara membandingkan dosis obat-obatan yang diresepkan dokter untuk pasien dengan panduan dosis obat yang terdapat dalam literatur Drug Information Handbook International edisi 17 (Lacy dkk., 2009), Pharmacotheraphy Handbook edisi 9 (Dipiro dkk., 2015) dan Pharmaceutical Care untuk Pasien Penyakit Artritis Rematik (Depkes RI., 2006). Analisis potensi interaksi obat dilakukan berdasarkan literatur Stockley's Drug Interactions (Baxter, 2008).

\section{Hasil dan Pembahasan Profil Pasien Osteoartritis}

Data yang digunakan dalam penelitian ini adalah data yang terdapat dalam rekam medis 85 pasien OA di Instalasi rawat jalan Rumah Sakit RSUD Dr. M. Ashari Pemalang periode MaretApril 2018. Pada rekam medis, sebagian besar pasien telah mengalami penyakit OA selama 1-2 tahun $(40 \%)$ dan banyak diderita oleh perempuan $(72,94 \%)$ dari pada laki-laki $(27,16 \%)$. Penyakit ini umumnya banyak dialami oleh perempuan usia di atas 50 tahun, atau memasuki masa menopause. Kelompok pasien ini umumnya akan mengalami penurunan fungsi hormon, terutama hormon estrogen yang akan berdampak pada berbagai fungsi fisiologis tubuh. Sintesis dan sekresi 
esterogen pada perempuan pada masa menopause akan menurun secara perlahan hingga akhirnya berhenti. Selama periode ini, kadar hormon akan berfluktuasi yang dapat mempengaruhi sistem reproduksi dan kesehatan tulang. Kadar estrogen yang menurun juga dapat menyebabkan fluktuasi hormon kalsitonin yang berdampak langsung pada kemampuan tulang dalam mengabsorpsi kalsium secara efisien (Arissa, 2013). Dalam penelitian ini, OA paling banyak diderita oleh pasien dengan rentang usia 46-55 tahun (39\%). Usia sangat erat kaitannya dengan terjadinya nyeri atau radang sendi. Semakin meningkat usia seseorang, umumnya akan diikuti dengan penurunan mobilitas yang menyebabkan pelemahan otot, ketegangan pada tulang rawan sendi dan dapat membuat tendon sobek (Depkes RI., 2006).

Latar belakang pendidikan pasien OA di RSUD Dr. M. Ashari Pemalang periode Maret-April 2018 lebih didominasi oleh pasien dengan pendidikan SD/sederajat (41\%). Tingkat pendidikan secara signifikan dapat mempengaruhi risiko dan perjalanan klinis dari terapi OA. Kualitas hidup pasien OA juga berkaitan dengan latar pendidikan pasien. Umumnya, pasien dengan latar belakang pendidikan yang tinggi akan memiliki kualitas hidup yang lebih baik dari pada pasien dengan riwayat pendidikan menengah dan rendah (Lopez-Castillo dkk., 2014).

Berdasarkan indeks massa tubuh (IMT), sebanyak 43,53\% pasien OA rawat jalan di RSUD Dr. M. Ashari Pemalang periode Maret-April 2018 adalah pasien dengan kategori overweight (IMT 25,00-29,99). Berat badan dapat mempengaruhi kesehatan sendi dan merupakan faktor risiko OA. Seseorang dengan berat badan berlebih lebih berisiko untuk mengalami OA dibandingkan orang dengan berat badan normal atau kekurangan berat badan (Khairani, 2013).

\section{Evaluasi Penggunaan Obat}

\section{Tepat Indikasi dan Tepat Pasien}

Hasil penelitian ini menunjukkan bahwa semua obat-obatan (100\%) yang diresepkan dokter untuk terapi OA pada pasien rawat jalan di RSUD Dr. M. Ashari Pemalang periode Maret-April 2018 telah tepat indikasi dan tepat pasien. Tepat indikasi berkaitan dengan kesesuaian antara obat yang diresepkan dokter dengan indikasi klinis penggunaan, yaitu untuk terapi OA sesuai dengan diagnosa dokter dan keluhan yang dialami pasien. Sementara itu, tepat pasien dapat didefinisikan bahwa obat yang diresepkan dokter tidak dikontraindikasikan dengan kondisi pasien, antara lain penyakit yang diderita, kehamilan, menyusui, usia lanjut dan bayi (Depkes RI., 2008).

\section{Evaluasi Tepat Dosis}

Tepat dosis adalah ketepatan dalam pemberian jumlah takaran dosis, frekuensi obat, dan cara penggunaan obat yang diberikan pada pasien (Depkes RI., 2008). Hasil penelitian ini menunjukkan bahwa ada 159 kasus peresepan obat dari 85 orang pasien OA rawat jalan di RSUD Dr. M Ashari Pemalang yaitu terdapat beberapa obat analgetik, suplemen baik itu tunggal maupun kombinasi. Adapun yang hanya suplemen glukosamin tanpa analgetik ada 10 pasien, analgetik tunggal 10 pasien, analgetik tunggal dan suplemen glukosamin 55 pasien, serta analgetik kombinasi dan suplemen glukosamin 10 pasien. Sebanyak $68(80,95 \%)$ kasus peresepan obat analgetik yang diresepkan telah tepat dosis. Sebanyak $16(19,05 \%)$ kasus peresepan obat analgetik tidak tepat dosis dan umumnya masuk ke dalam kategori dosis kurang, terutama pada peresepan parasetamol (5 kasus), dexketoprofen (8 kasus), dan Na diklofenak (3 kasus). Sedangkan peresepan yang mengandung suplemen glukosamin 71 kasus dosis kurang (250-750 mg/hari), dan 4 kasus (1500 $\mathrm{mg} / \mathrm{hari}$ ) dosis sesuai literatur karena hal ini juga disesuaikan dengan kondisi klinis pasien.

Penatalaksanaan terapi OA diberikan berdasarkan tingkat keparahan dan rasa nyeri yang diderita pasien, sehingga dosis kurang dimungkinkan menyesuaikan dengan kondisi klinis pasien dan karena adanya kombinasi obat untuk meminimalkan efek samping. Parasetamol diindikasikan pada pasien dengan keluhan nyeri ringan-sedang. Parasetamol tunggal yang diberikan pada 3 pasien dengan dosis $2 \times 500 \mathrm{mg}$ (1000 mg/hari) sehingga dosis yang diberikan di bawah rentang dosis karena menurut Pharmacotheraphy Handbook edisi 9 menyatakan bahwa dosis parasetamol 
tunggal untuk penanganan rasa nyeri pada osteoartritis yaitu 325-650 mg setiap 4-6 jam atau 1000 mg 3-4 kali per hari. Walaupun demikian, pasien mendapatkan terapi glukosamin yang merupakan suplemen sendi yang tersusun dari glukosa dan glutamin yang mampu untuk memperbaiki kondisi tulang rawan. Pada kasus ini terdapat pula 2 pasien yang mendapatkan kombinasi parasetamol 2x500 mg/hari dengan dexketoprofen $75 \mathrm{mg} / \mathrm{hari}$ dan parasetamol 2x500 $\mathrm{mg} / \mathrm{hari}$ dengan meloxicam $15 \mathrm{mg} / \mathrm{hari}$, kombinasi ini cukup baik untuk mengatasi nyeri sedang hingga berat yang dialami oleh pasien.

Terdapat 6 pasien yang mendapat terapi dexketoprofen tunggal yang diberikan dengan dosis $2 \times 25 \mathrm{mg}$ (50 mg/hari) dan 2 pasien dengan dosis $1 \times 25 \mathrm{mg}(25 \mathrm{mg} / \mathrm{hari})$. Standar dosis dexketoprofen pada Drug Information Handbook International (DIH) yaitu 25-50 mg/6-8 jam. Terdapat 3 pasien yang mendapatkan Na diklofenak dengn dosis $2 \times 25 \mathrm{mg}(50 \mathrm{mg} / \mathrm{hari})$, dosis ini di bawah rentang standar dosis Na diklofenak pada DIH yaitu 100-150 mg/hari dalam dosis terbagi 2-3. Pemberian dosis di bawah rentang akan mengakibatkan rasa nyeri yang diderita pasien kurang tertangani dengan baik, namun tingkat nyeri yang diderita pasien kemungkinan tergolong nyeri ringan, sehingga cukup dengan dosis tersebut. Data peresepan obat dengan dosis kurang dapat dilihat pada tabel I dan II.

Tabel I. Evaluasi Tepat Dosis Obat Analgetik pada Pasien Osteoartritis di Instalasi Rawat Jalan RSUD Dr. M. Ashari Pemalang Periode Maret-April 2018

\begin{tabular}{ccc}
\hline Evaluasi & Jumlah Kasus & Persentase (\%) \\
\hline Tepat Dosis & 68 & 80,95 \\
Tidak Tepat Dosis (Dosis kurang) & 16 & 19,05 \\
\hline Total & $\mathbf{8 4}$ & $\mathbf{1 0 0}$ \\
\hline
\end{tabular}

Tabel II. Evaluasi Obat Dosis Kurang pada Pasien Osteoartritis di Instalasi Rawat Jalan RSUD Dr. M. Ashari Pemalang Periode Maret-April 2018

\begin{tabular}{ccccc}
\hline Nama Obat & $\begin{array}{c}\text { Dosis yang } \\
\text { diberikan per hari } \\
(\mathbf{m g})\end{array}$ & $\begin{array}{c}\text { Dosis } \\
\text { literatur per } \\
\text { hari (mg) }\end{array}$ & $\begin{array}{c}\text { Jumlah } \\
\text { Kasus }\end{array}$ & $\begin{array}{c}\text { Persentase } \\
(\%)\end{array}$ \\
\hline Parasetamol & 1000 & $1300-2600$ & 5 & 5,75 \\
Glukosamin & 250 & & 42 & 48,28 \\
Dexketoprofen & 500 & 1500 & 23 & 26,44 \\
Na Diklofenak & 750 & & 6 & 6,89 \\
\hline Total & 25 & $75-200$ & 2 & 2,30 \\
\hline
\end{tabular}

\section{Potensi Interaksi Obat yang Mungkin Muncul dalam Terapi}

Interaksi obat adalah adanya pengaruh suatu obat terhadap obat lain di dalam tubuh. Efek obat dapat bertambah atau berkurang akibat adanya interaksi obat yang terjadi. Hasil penelitian menunjukkan bahwa peresepan obat OA pada 26 orang pasien rawat jalan $(30,58 \%)$ di RSUD Dr. M. Ashari Pemalang Periode Maret-April 2018 berpotensi mengalami interaksi obat dengan obat lainnya, dengan jumlah kasus sebanyak 29 kasus interaksi obat (tabel III). Pasien OA rawat jalan di RSUD Dr. M. Ashari Pemalang Periode Maret-April 2018 mendapatkan beberapa obat, baik untuk pengobatan OA maupun obat untuk penyakit lain yang sedang diderita.

Potensi interaksi antara satu golongan obat NSAID (Na diklofenak dan ibuprofen, meloxicam dan dexketoprofen, serta asam mefenamat dan dexketoprofen) tergolong interaksi yang minor, namun hal ini meningkatkan risiko perdarahan saluran cerna bagian atas. Pengobatan OA dengan NSAID dan golongan steroid memiliki potensi meningkatkan risiko luka pada gastrointestinal, sehingga perlu monitoring gejala atau keluhan pada lambung pasien. Potensi interaksi obat NSAID 
dengan candesartan, valsartan, irbesartan dapat menurunkan efek antihipertensi, sehingga perlu monitoring tekanan darah pasien. Potensi interaksi obat antidiabetes oral dengan golongan NSAID dapat meningkatkan risiko hipoglikemia, sehingga perlu monitoring kadar gula darah (Baxter, 2008 dan Anonim ${ }^{\mathrm{a}}$, 2019).

Tabel III. Potensi Interaksi Obat yang Merugikan pada Pengobatan Osteoartritis di Instalasi Rawat Jalan Instalasi Rawat Jalan RSUD Dr. M. Ashari Pemalang Periode MaretApril 2018.

\begin{tabular}{|c|c|c|c|c|}
\hline No. & Obat & $\begin{array}{c}\text { Dampak dari } \\
\text { Interaksi Obat } \\
\end{array}$ & $\begin{array}{l}\text { Jumlah } \\
\text { (Kasus) }\end{array}$ & $\begin{array}{c}\text { Persentase } \\
(\%) \\
\end{array}$ \\
\hline 1 & NSAID + NSAID & $\begin{array}{l}\text { Meningkatkan risiko } \\
\text { terjadinya kerusakan } \\
\text { gastrointestinal }\end{array}$ & 3 & 10,34 \\
\hline 2 & NSAID + Metil Prednisolon & $\begin{array}{l}\text { Meningkatkan risiko } \\
\text { pendarahan di saluran } \\
\text { cerna dan ulserasi }\end{array}$ & 5 & 17,24 \\
\hline 3 & $\begin{array}{l}\text { NSAID (Meloxicam, } \\
\text { Ketoprofen, Dexketoprofen, Na } \\
\text { Diklofenak) + Antagonis } \\
\text { Reseptor Angiotensin II } \\
\text { (Candesartan, Valsartan, } \\
\text { Irbesartan) }\end{array}$ & $\begin{array}{l}\text { Efek antihipertensi } \\
\text { berkurang, peningkatan } \\
\text { potasium }\end{array}$ & 15 & 51,72 \\
\hline 4 & $\begin{array}{l}\text { NSAID (Meloxicam, } \\
\text { Dexketorofen, Ketoprofen) + } \\
\text { Antidiabetik (Metformin, } \\
\text { Glimepiride) }\end{array}$ & $\begin{array}{l}\text { Terjadi efek } \\
\text { hipoglikemia }\end{array}$ & 4 & 13,80 \\
\hline 5 & $\begin{array}{l}\text { NSAID (Meloxicam, } \\
\text { Piroxicam) + Prednison }\end{array}$ & $\begin{array}{l}\text { Meningkatkan risiko } \\
\text { pendarahan di saluran } \\
\text { cerna dan ulserasi }\end{array}$ & 2 & 6,90 \\
\hline \multicolumn{3}{|c|}{ Total } & 29 & 100 \\
\hline
\end{tabular}

Interaksi obat menjadi penting secara klinik apabila meningkatkan toksisitas atau mengurangi efektifitas obat. Kejadian interaksi dipengaruhi oleh variasi individual misalnya pasien lanjut usia, atau yang berpenyakit tertentu, dan juga faktor metabolisme individu yang berbeda-beda serta genetik (Gunawan, 2016). Interaksi meloxicam dan ketoprofen dengan sukralfat, ketoprofen dan $\mathrm{Na}$ diklofenak dengan ranitidin, tidak memiliki efek signifikan secara klinis. Pemberian sukralfat atau ranitidine kemungkinan untuk mengatasi keluhan pasien seperti tidak nyaman di perut akibat penggunaan jangka panjang obat dalam pengatasan OA. Selain itu, penggunaan NSAID pada usia lanjut disarankan untuk menambahkan golongan pompa proton inhibitor, hal ini terbukti mengurangi efek samping perdarahan pada lambung (Anonim $\left.{ }^{\mathrm{b}}, 2019\right)$.

\section{KESIMPULAN}

Pasien OA rawat jalan di Rumah Sakit RSUD Dr. M. Ashari Pemalang periode MaretApril 2018 memiliki karakteristik telah mengidap penyakit ini selama 1-2 tahun (40\%), sebagian besar perempuan (72,94\%) dengan rentang usia 46-55 tahun (39\%). Pasien umumnya memiliki tingkat pendidikan SD/sederajat (41\%) dan $43,53 \%$ diantaranya adalah pasien dengan kategori overweight (IMT 25,00-29,99). Semua obat-obatan yang diresepkan dokter untuk terapi OA telah tepat indikasi dan tepat pasien (100\%). Sebanyak $80,95 \%$ obat-obatan yang diresepkan telah tepat 
dosis dan 19,05\% kasus peresepan obat masuk ke dalam kategori dosis kurang. Potensi interaksi obat terjadi pada 30,58\% pasien dengan jumlah kasus sebanyak 29 kasus.

\section{DAFTAR PUSTAKA (11pt)}

Anonima, 2019, Drug Interaction Checker, dikutip dari: https://reference.medscape.com/druginteractionchecker, diakses pada tanggal 22 Desember 2019.

Anonim $^{\mathrm{b}}$, 2019, American Geriatrics Society 2019 Updated AGS Beers Criteria for Potentially Inappropriate Medication Use in Older Adults, Journal American Geriatrics Society, 67(4): 674-694.

Arissa, M.I., 2013, Pola Distribusi Kasus Osteoarthritis di RSU Dokter Soedarso Pontianak Periode 1 Januari 2008-31 Desember 2009, Jurnal Mahasiswa Program Studi Profesi Dokter Fakultas Kedokteran Universitas Tanjungpura, 1(1):11-12.

Baxter, K., 2008, Stockley's Drug Interactions, $8^{\text {th }}$ ed. London: Pharmaceutical Press, 133-198

Buys, L.M. and Elliot, M.E., 2008, Osteoarthritis in Dipiro, J.T, Buys, Lucinda M, et al. Pharmacoterapy Pathophysiologic Approach, $7^{\text {th }}$ Ed., McGraw-Hill Education, USA, 101

Depkes RI., 2006 Pharmaceutical Care untuk Pasien Penyakit Arthritis Rematik, Penerbit Direktorat Bina Farmasi Komunitas dan Klinik, Departemen Kesehatan, Jakarta, 19-21

Depkes RI, 2008, Materi Pelatihan Peningkatan Pengetahuan dan Keterampilan Memilih Obat Bagi Tenaga Kesehatan, Penerbit Buku Kedokteran EGC, Jakarta, 6-7

Dipiro, J.T., Dipiro J.V., Wells, B.G., and Scwinghammer, T.L., 2015, Pharmacotheraphy Handbook. $9^{\text {th }}$ E. Mc Graw Hill Companies Inc., New York, 9-15

Gunawan, S., G., 2016, Farmakologi dan Terapi, Edisi 6, Departemen Farmakologi dan Teurapetik, Fakultas Kedokteran, Universitas Indonesia, Jakarta, 868-869

Khairani, Y., 2013, Hubungan Umur, Jenis Kelamin, IMT, dan Aktivitas Fisik dengan Kejadian Osteoartritis Lutut, Jambi Medical Journal,1(1): 6-7

López-Castillo, C.A., Calderón-Rojas, R., Amaya-Amaya, J., DeSanVicente-Célis, Z., Mantilla, R.D. and Rojas-Villarraga, A., 2014, Impact of Educational Level on Rheumatoid Arthritis: A Systematic Review, Revista Colombiana de Rheumatologia, 21(4): 201-212

Lacy, C.F., Amstrong, L.L., Goldman, P. and Lance, L.L., 2009, Drug Information Handbook International, $17^{\text {th }}$ Ed, Lexi-Comp Inc., Ohio

Sukandar, E.Y., Andrajati R., I Sigit, J., Adnyana, I.K., Setiadi, A.A.P., dan Kusnandar, 2008, ISO Farmakoterapi, PT.ISFI Penerbitan, Jakarta, 576

Woolf, A.D. and Pfleger, B., 2003, Burden of major musculoskeletal conditions. Bull World Health Organization, Avaible from : http://www.who.int/chp/topics/rheumatic/en/, diakses tanggal 13 Maret 2018 